\title{
REPLACEMENT OF THE BRICK BY PET BOTTLE WITH M-SAND: NEW INNOVATIVE CONSTRUCTION MATERIAL
}

\author{
Ravikumar $\mathbf{S}^{1}$ \\ ${ }^{1}$ Assistant Professor, Department Civil Engineering, Vaishnavi School of Architecture and Planning, Hyderabad,India
}

\begin{abstract}
This Clay bricks are most commonly used in all kind of buildings such as for the load \& non load bearing walls and columns.This bricks withstands high volume and increase the weight of the building. These are most commonly used to construct the walls and columns and in RC structure as non load bearing walls. This project is mainly based on replacement of PET (Polyethylene terephthalate) bottles filled with M-sand (Manufactured Sand) instead of bricks. The empty bottle alone cannot withstand the load, so it is filled with M-sand and Natural sand ( $N$-sand) It is also known as pet bottle bricks. The strength obtained is greater than the bricks. It reduces the carbon emissions during burning of clay brick during the manufacture of brick. It is eco friendly and energy efficient. The cost comparison also done between normal clay brick work with PET bottle brick work for cement mortar ratio of 1:3 masonry
\end{abstract}

Keywords: Polyethylene Terephthalate, M-Sand , N-Sand, Clay Bricks

\section{INTRODUCTION}

\subsection{General}

Bricks are the most commonly used building material. It's made from soil generally clay is molded to rectangular blocks of standard size, which are dried and then burnt at a high temperature. This makes a dense and compact material called brick.

In the manufacture of bricks, there are four stages:

(i ) Preparation of earth or clay

(ii) Moulding of brick

(iii) Drying of bricks

(iv) Burning of bricks

\subsection{PET Bottle}

Polyethylene terephthalate (sometimes written poly(ethylene terephthalate)), commonly abbreviated PET, PETE, is a thermoplastic polymer resin of the polyester family and is used in synthetic fibers; beverage, food and other liquid containers; thermoforming applications; and engineering resins often in combination with glass fiber. PET can be semi-rigid to rigid, depending on its thickness, and it is very lightweight. It makes a good gas and fair moisture barrier, as well as a good barrier to alcohol and solvents. It is strong and impact-resistant. It is naturally colorless with a high transparency.

While most thermoplastics are, recyclable, PET bottle recycling is more practical than any other plastic applications.

\section{NEED OF REPLACEMENT}

Clay brick is now expensive due to cost of indirect materials of wood materials, transportation cost and labor cost. The process of burning bricks emits $(\mathrm{CO} 2)$ carbon dioxide to the environmental so this causes environmental problems. Preparation of clay bricks consumes less time and energy but as the clay brick to burning in the kiln to time and energy consumed. Environmental effect transportation and other constraints make the use of clay bricks less attractive.

PET Bottle can last as long as 300 years (undoubtedly longer than the cement used to bind the bottles together in the walls and columns).Clay bricks are set to be affected by vegetation, over burning, etc.But the pet bottle brick may not affected by vegetation, because it was covered by the mud or sands inside of the pet bottles. So there is no vegetation growth in structures.

When compared to pet bottles there are no such drawbacks .Especially the plastic wastes in environmental is to be reduced because it reduces the vegetation growth and it does not decompose soon.

This method also conserves the heat energy, time, and this construction is satisfied sustainable concepts of conservation of energy reuse and recycles the wastes. So it is called as green construction.

\section{SCOPE}

- To provide a most economical brick

- It should be easily adopt to the field

- Using the waste in a useful manner.

- To reduce the cost of the construction

- To make the maximum usage of locally available material

- $\quad$ To minimize the carbon emission from the kiln 


\section{MATERIALS USED}

Pet bottle : PET a thermoplastic polymer resin of the polyester family and is used in synthetic fibers; beverage, food and other liquid container

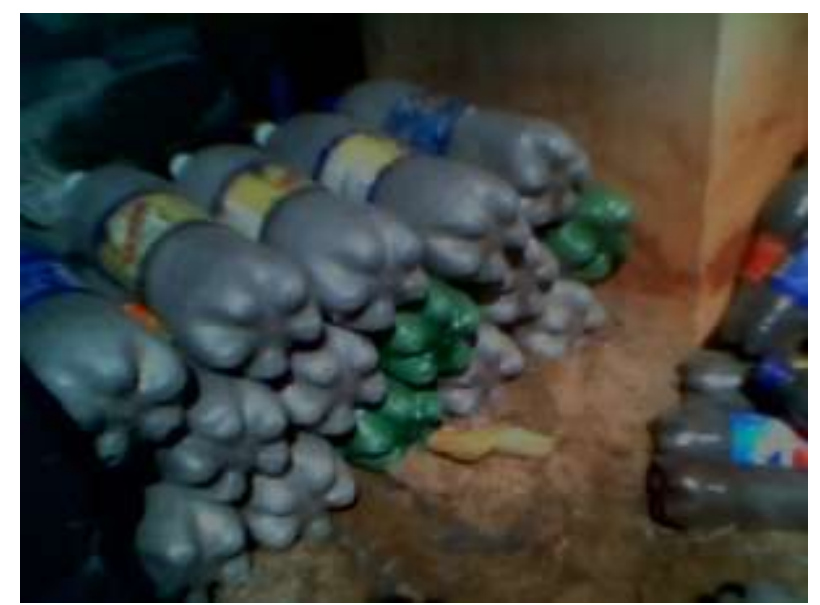

Fig 1 Petbottle

Msand : Manufactured sand is a substitute of river for construction purposes sand produced from hard granite stone by crushing. The crushed sand is of cubical shape with grounded edges, washed and graded to as a construction material. The size of manufactured sand (M-Sand) is less than $4.75 \mathrm{~mm}$



Fig 2 M-Sand

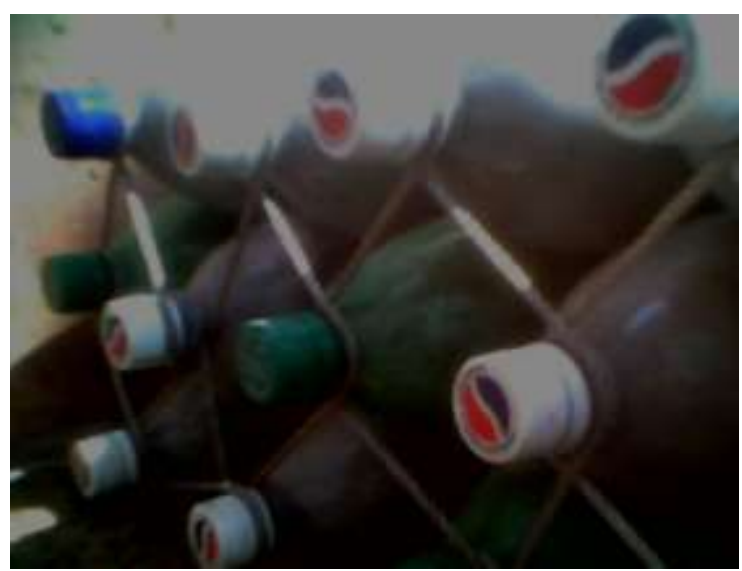

Fig 3 Nylon thread for tie

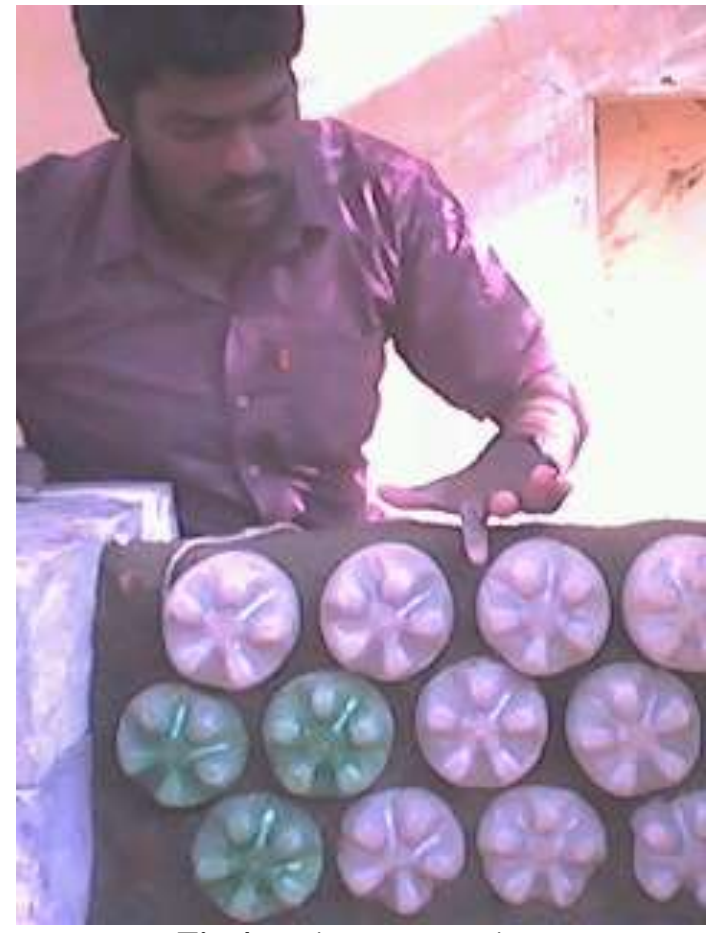

Fig 4 During construction

\section{CONSTRUCTION PROCEDURE PET} BOTTLE BRICK WORK

\subsection{Procedure}

- Our first step is to collect as many discarded plastic bottles as much as required

- $\quad$ Take the bottles, fill them with M-sand, sealed and then paste them with a mixture made of earth, clay, sawdust and a little cement to provide additional strength and durability.

- Now lay the bottles one by one on this bed and tie them to each other as shown in the picture. After laying a course, fill the inside area with cement, clay or rubble .

- If we want to make more courses, make sure that we knot each bottle of the underlying course with the above course as shown in the picture. This is to impart more strength to the structure.



Fig 5 PET bottle brick1 


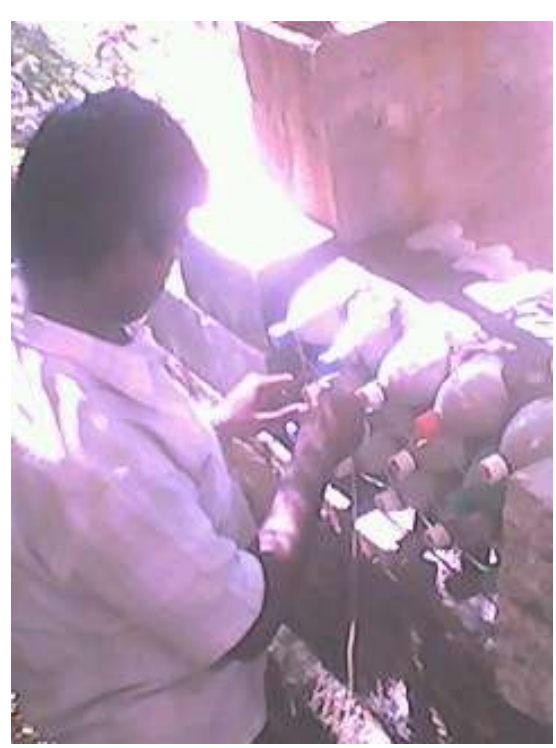

Fig 6 Construction



Fig 7 Curing Time

\section{EXPERIMENTAL WORK ON PET BOTTLE}

\section{BRICK}

\subsection{Classification and Characteristics of Bricks as} per is-1077 - 1973

Tests for the acceptance of bricks for building construction

- Dimension and tolerance test

- Compressive strength test

- Water absorption test

- Efflorescence test

\section{SPECIMENS AND TESTING DETAILS}

The following specimens are pet bottle filled with the dry sand, clay, and m-sand

1) 3 no's 2 liter bottle 3 no's of 600 milliliter bottles are filled with dry sand, clay and $\mathrm{m}$-sands for the determination of compressive load test of pet bottle brick.

2) 15 no's of bottles for dimension tests

3) 3 no's both 2 liter and 600 milliliter bottles of for determination of water absorption test

4) 3 no's both 2 liter and 600 milliliter bottles of for determination of efflorescence test
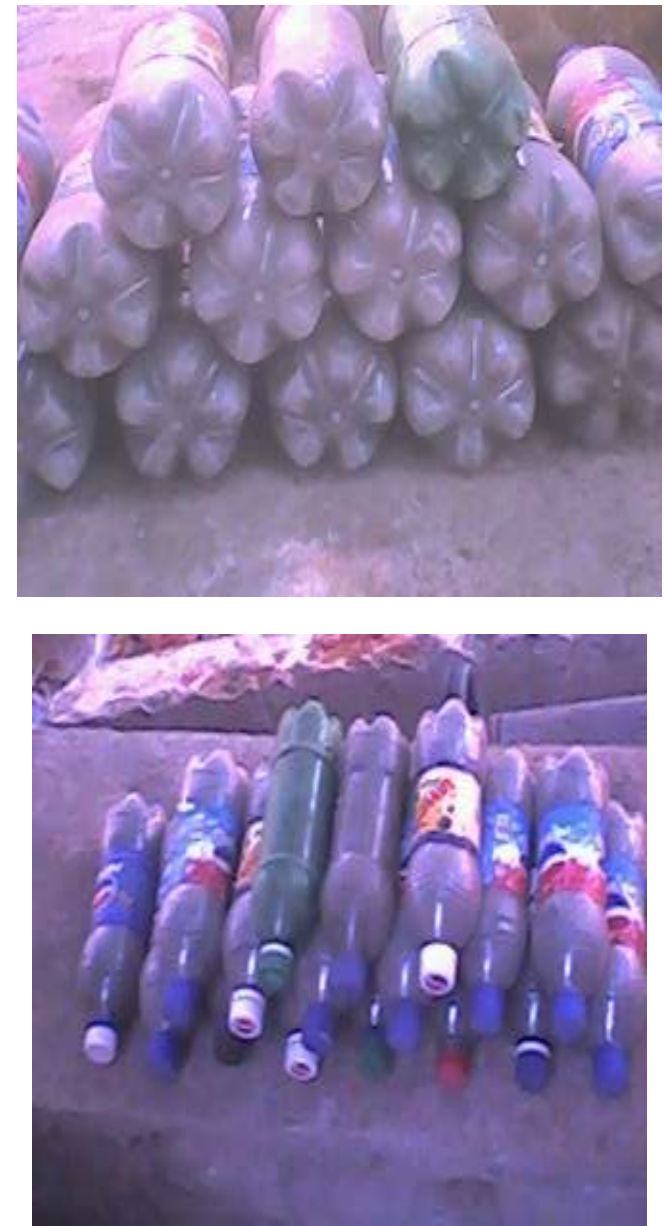

Fig 8 PET bottle with $\mathrm{N}$-sand

Compressive load test:In the test, the compressive load for the pet bottle is found out by using compression testing machine or universal testing machine. Instead of: the Compressive strength of test because its contact area is difficult to find as single bottle area.

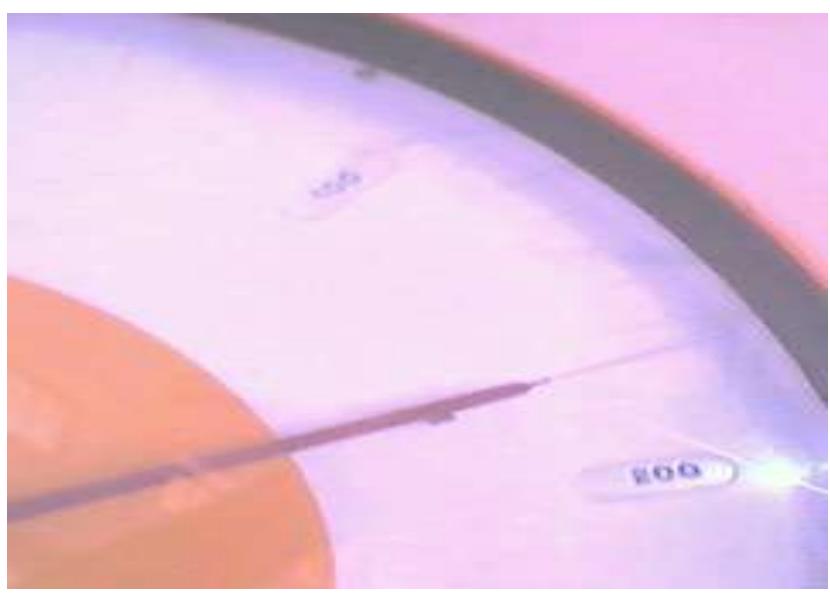






Fig 9 Compression Test

Water absorption test:if the water absorption capacity of a brick is more, its strength will be comparatively low.For first class bricks, the water absorption capacity should not be more than $20 \%$ by weight as per IS 3495- PART 2. This same procedure will follow for pet bottle brick work.

Efflorescence test :This test is performed to know the presence of any alkaline matter in the bricks. But in this pet bottle bricks, cover the filler materials by means of pet bottles. So this method is not suitable for this pet bottle bricks.

\section{RESULTS AND DISCUSSIONS}

Table 1 compressive load test results

\begin{tabular}{|l|l|}
\hline SPECIMEN & LOAD(KN) \\
\hline 2 liter pet bottle filled with M-sand & 180 \\
\hline 2 liter pet bottle filled with N-sand & 110 \\
\hline 2 liter pet bottle filled with clay & 100 \\
\hline Normal clay brick & 170 \\
\hline
\end{tabular}

Table 2 Water absorption test:

\begin{tabular}{|l|l|}
\hline SPECIMEN & $\begin{array}{l}\text { water absorption capacity } \\
\text { in \% of self weight }\end{array}$ \\
\hline $\begin{array}{l}\text { with } \text { liter pet bottle filled } \\
\text { 2 liter pet bottle filled } \\
\text { with N-sand }\end{array}$ & 0 \\
\hline $\begin{array}{l}2 \text { liter pet bottle filled } \\
\text { with clay }\end{array}$ & 0 \\
\hline Normal clay brick & 15 \\
\hline
\end{tabular}

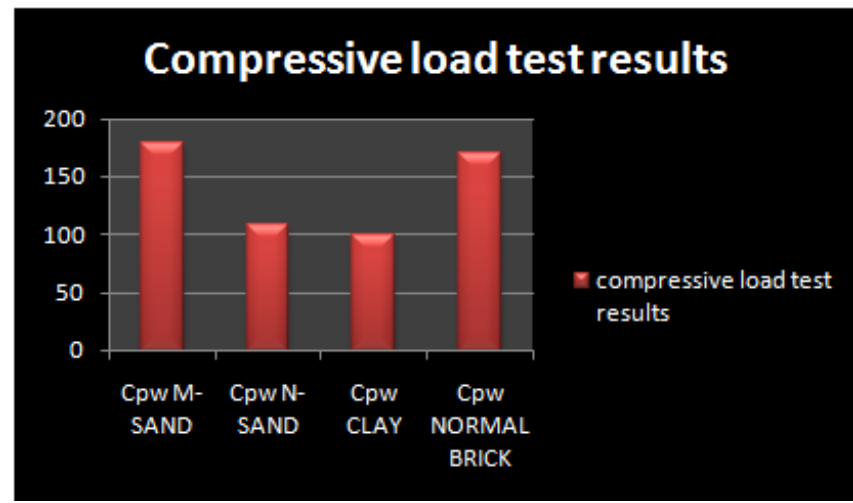

Fig 10 compressive load test

Cost Comparision Of Normal Brick Work To Pet Bottle Brick

Total cost of clay brick work $1: 3 \quad=3888.01 \mathrm{Rs} / \mathrm{m}^{3}$

Total cost of pet bottle brick $1: 3 \quad=2899.275$

$\mathrm{Rs} / \mathrm{m}^{3}$

\section{CONCLUSION}

This is an effective solution for reusing the plastic. Bottles have the following advantages over bricks and other construction materials.

- Low cost - We know how much a bottle costs!

- Non-Brittle - (Unlike bricks)

- Absorbs abrupt shock loads - Since they are not brittle, there can take up heavy loads without failure

- . Re-usable

- Less construction material

- $\quad$ Easy to build

- Green Construction

- good aesthetic view

Hence, I conclude that PET bottle masonry is cost effective compared to brick masonry. It is also one of the first and fore most step for initiation of building concept.

\section{REFERENCES}

[1]. Polymer activity - pet bottles written by "Mary Harris, Missouri Polymer Ambassador"

[2]. In the reference of website of "www.eco-tecnologia.com encyclopidia"

[3]. IS-1077 - 1973 Common Burnt Clay Building Bricks Specification

[4]. IS 3495-1992 Methods of tests of burnt clay building bricks: Part 1 